\title{
Aging Process of Cadmium, Copper, and Lead under Different Temperatures and Water Contents in Two Typical Soils of China
}

\author{
Guannan Liu $\mathbb{D}^{1},{ }^{1}$ Zhanqiu Yu, ${ }^{2}$ Xinhui Liu $\mathbb{D}^{3},{ }^{3}$ Wei Xue, ${ }^{4}$ Liming Dong, ${ }^{2}$ \\ and Yongbing Liu $\mathbb{D}^{5}$ \\ ${ }^{1}$ MNR Key Laboratory of Metallogeny and Mineral Assessment, Institute of Mineral Resources, CAGS, Beijing 100037, China \\ ${ }^{2}$ Key Laboratory of Cleaner Production and Integrated Resource Utilization of China National Light Industry, \\ School of Ecology and Environment, Beijing Technology and Business University, \\ Beijing 100048, China \\ ${ }^{3}$ State Key Laboratory of Water Environment Simulation, School of Environment, Beijing Normal University, \\ 100875 Beijing, China \\ ${ }^{4}$ Agricultural and Environmental Chemistry, University of CA, Davis, CA, USA \\ ${ }^{5}$ Key Laboratory of Eco-Geochemistry, Ministry of Natural Resources, National Research Center for Geoanalysis, \\ Beijing 100037, China
}

Correspondence should be addressed to Xinhui Liu; xhliu@bnu.edu.cn and Yongbing Liu; liuyongbing21@163.com

Received 15 January 2020; Revised 6 April 2020; Accepted 15 April 2020; Published 28 May 2020

Academic Editor: Pedro Avila Pérez

Copyright (C) 2020 Guannan Liu et al. This is an open access article distributed under the Creative Commons Attribution License, which permits unrestricted use, distribution, and reproduction in any medium, provided the original work is properly cited.

Aging process of exogenous heavy metals in soil is significant for reducing their environmental risk due to the redistribution of species of soil heavy metals. A red soil (ultisol) and a brown soil (alfisol) were selected to investigate the aging process of cadmium $(\mathrm{Cd})$, copper $(\mathrm{Cu})$, and lead $(\mathrm{Pb})$ under different regimes of temperature and water content. Most introduced heavy metals were all transformed from dissolved fraction to more stable fractions within 5 days of incubation. During incubation, most $\mathrm{Pb}$ existed in the fraction bound to Fe/Mn oxides, while exchangeable and carbonate-associated fraction was the dominant portion for Cd and $\mathrm{Cu}$, suggesting that the transformation rate followed the order: $\mathrm{Pb}>\mathrm{Cu}>\mathrm{Cd}$. The exchangeable and carbonate-associated fraction in red soil, which was characterized with higher $\mathrm{pH}$ and $\mathrm{Fe} / \mathrm{Al} / \mathrm{Mn}$ oxides and lower organic matter (OM), was significantly higher than that in brown soil, implying that soil OM was the important factor affecting the aging process of soil heavy metals in the present study. In addition, increases of temperature and soil water content can accelerate the transformation of most introduced $\mathrm{Cd}, \mathrm{Cu}$, and $\mathrm{Pb}$ to more stable forms in the soils. The results indicated that soil properties, environmental factors (i.e., temperature and water content), types of heavy metals, and pollution time can significantly affect the aging process of exogenous heavy metals.

\section{Introduction}

Soil pollution by heavy metals has led to great concerns in the past few decades [1-3]. Heavy metals in soil can be absorbed by crops and accumulated in foods, eventually generating adverse impact on plant growth and threatening human health through the food chain [4-8]. In addition, excess heavy metals in surface soil can migrate downward easily to pollute groundwater inducing high health risk $[9,10]$. Excess heavy metals in soil are often derived from anthropogenic activities, such as mining, fertilization, traffic, and industry [2,11-15]. For example, in acid mine drainage, concentrations of heavy metals can be up to tens of mg per liter, even hundreds of mg per liter [16], which often leads to severe heavy metal pollution of soils surrounding mines.

When these exogenous heavy metals, especially soluble form, were discharged into the soil, they can be fixed via incorporation into crystal lattices, diffusion into micropores, or formation of metal precipitates on the surfaces of soil minerals [17] and present relatively low bioavailability and mobility. This progress terms the aging of heavy metals and is crucial for reducing the environmental risk of soil heavy metals [18]. The aging process of soil heavy metals is time dependent [19]. The 
short-term aging process is predominantly controlled by solidliquid distribution (mainly adsorption). Previously research reported that rapid reduction of bioavailable heavy metals often occurred within 10-20 days after adding heavy metals [20-22]. After that, heavy metals adsorbed on the surface of soil are further slowly fixed by micropore diffusion, cavity entrapment, occlusion in solid phases by coprecipitation, surface precipitation, and so on $[23,24]$. The two steps of the aging process are both affected significantly by types of heavy metals, soil properties, and circumstance conditions. It was reported that Cd shows a lower tendency to be fixed into unavailable forms than $\mathrm{Zn}$ or $\mathrm{Cu}$ [25]. Soil organic matter (OM), clay and $\mathrm{Fe} / \mathrm{Al}$ oxides, meanwhile, are significant for aging of soil heavy metals $[26,27]$. It was reported that $\mathrm{Cu}$ trends to bind onto $\mathrm{OM}$ in some size fractions of soil particles [28]. Al oxides play a more crucial role than Fe oxides in controlling the rate of arsenic (As) aging [29]. Aging process can be accelerated or retarded obviously under different circumstance conditions as well. High temperature generally increases and accelerates the diffusion of heavy metal ions in micropores and form inner surface, further accelerating the transformation of soil heavy metals $[23,30]$. Zheng et al. reported that waterlogging of soil facilitate the transformation of heavy metals from bioavailable fraction to a more stable fraction by changing soil $\mathrm{pH}, \mathrm{Eh}$, and hydrous oxide content [20]. Higher salinity also can retard the stabilization of heavy metals during aging [31].

Though the aging of soil heavy metals has been studied extensively under various circumstance conditions, some inconsistent results of the aging process of soil heavy metals have been reported. Liang et al. reported that only $1.1-8.1 \%$ decreased in $\mathrm{Pb}$ bioaccessibility during 76 weeks [32]. However, Jalali and Khanlari obtained that average $79 \%$ heavy metals $(\mathrm{Cd}, \mathrm{Cu}, \mathrm{Pb}$, and $\mathrm{Zn})$ become nonexchangeable fraction after 28 days of incubation [33]. It was also found that the percent of exchangeable fractions of heavy metals $(\mathrm{Cd}, \mathrm{Cu}$, and $\mathrm{Pb})$ to nonexchangeable fraction decreased by $32.39 \%-74.11 \%$ after 35 days of incubation [20]. Thus, it is meaningful to further explore the aging process of soil heavy metals. In addition, the $\mathrm{pH}$ value of red soil is generally lower than brown soil, and the content of metal oxides of red soil is generally higher than brown soil. However, alkaline red soil located in limestone area is typical in southern China and some acid brown soil also can be found in northern China. In the present study, an alkaline red soil (ultisol) containing higher metal oxides and an acidic brown soil (alfisol) containing lower metal oxides, which was not consistent with soil properties in most other studies, were used to study the aging process of heavy metals under different regimes of temperature and water content. This study can provide more information for aging mechanisms of soil heavy metals which contributes to assessing environmental risk of soil heavy metal pollution.

\section{Material and Methods}

2.1. Soil Sampling and Characterization. Red and brown surface soils $(0-20 \mathrm{~cm})$ were sandy loam ultisol and loamy sand alfisol and were collected from a hilly forest in Fujian Province and farmland in Shandong Province, respectively, in China. The soil samples were air-dried, sieved through a
$2 \mathrm{~mm}$ polyethylene sieve, and then stored in polyethylene Ziploc bags before further analysis and soil incubation. Soil $\mathrm{pH}$ was measured with a $\mathrm{pH}$ meter (Mettler Toledo FE20, Switzerland) at a soil to water ratio of $1: 2.5$. Soil texture was analyzed using a laser particle size analyzer (Microtrac S3500, USA). Soil OM was measured by the $\mathrm{K}_{2} \mathrm{Cr}_{2} \mathrm{O}_{7}$ oxidation method [34]. Free crystalline and amorphous oxides $\mathrm{Al}, \mathrm{Fe}$, and $\mathrm{Mn}$ (DCB-Al, DCB-Fe, and DCB-Mn) were extracted by dithionite-citrate-bicarbonate (DCB) extraction [34]. Cation exchange capacity (CEC) was determined by the $\mathrm{BaCl}_{2}$ compulsive exchange method [35]. Subsamples of soils $(0.2 \mathrm{~g})$ were digested with $3 \mathrm{~mL} \mathrm{HNO}_{3}, 1 \mathrm{~mL} \mathrm{HClO}_{4}$, and $1 \mathrm{~mL} \mathrm{HF}$ in closed Teflon vessels for $5 \mathrm{~h}$ at $165^{\circ} \mathrm{C}$. After cooling, the vessels were transferred to an electric hot plate $\left(160^{\circ} \mathrm{C}\right)$ to eliminate silicon and any remaining HF. After the white smoke disappeared, the samples were taken off, and $1 \mathrm{~mL} \mathrm{HNO}_{3}$ was added, and then were adjusted to $10 \mathrm{~mL}$ with ultrapure water to measure heavy metals by inductively coupled plasma-optical emission spectrometry (ICP-OES) (SPECTRO ARCOS EOP, SPECTRO Analytical Instruments $\mathrm{GmbH}$, Germany) [2]. To ensure analytical quality, geochemical standard soils (GSS-1 and GSS-2), provided by the National Research Center for Geoanalysis of China, were used to validate the analytical method. The recoveries of the standard samples ranged from $90 \%$ to $110 \%$.

2.2. Soil Incubation. $50 \mathrm{~g}$ of the soil sample was weighed into a $100 \mathrm{~mL}$ plastic beaker. A $5 \mathrm{~mL}$ of the mixed stocked solution of $\mathrm{Cu}\left(\mathrm{NO}_{3}\right)_{2}(\mathrm{Cu}: 2 \mathrm{~g} / \mathrm{L}), \mathrm{Pb}\left(\mathrm{NO}_{3}\right)_{2}(\mathrm{~Pb}: 2 \mathrm{~g} / \mathrm{L})$, and $\mathrm{Cd}\left(\mathrm{NO}_{3}\right)_{2}(\mathrm{Cd}: 30 \mathrm{mg} / \mathrm{L})$ was added to the soil. The amounts of metals spiked were $200 \mathrm{mg} / \mathrm{kg}$ for $\mathrm{Cu}$ and $\mathrm{Pb}$ and $3 \mathrm{mg} / \mathrm{kg}$ for $\mathrm{Cd}$, respectively, which were higher than the risk screening values for soil contamination of the agricultural land of China (GB 15618-2018) [36]. Certain water content of the incubation soils was adjusted by adding deionized water. All samples were mixed thoroughly and then covered with a piece of parafilm with some pores to allow air influx and avoid the evaporation of soil water. For the experiment of temperature effect, all soil samples were stored in the dark at $5,10^{\circ} \mathrm{C}$, and $25^{\circ} \mathrm{C}$; the deionized water was added to maintain the soil water content of $20 \%$ every 2 days. For the experiment of water content effect, all soil samples were subjected to four water content conditions (i.e., $10 \%, 20 \%$, $30 \%$, and waterlogging (a $1 \mathrm{~cm}$ layer of water over the soil samples) ) and stored in the dark at $25^{\circ} \mathrm{C}$. Soils were sampled at different aging periods $(5,15,45,85$, and 145 days) after adding heavy metals, then analyzed for their geochemical fractions. All treatments were conducted in triplicate.

2.3. Geochemical Fraction Analysis of Heavy Metals. The sequential extraction of heavy metals in soils was carried out following the modified European Community Bureau of Reference (BCR) sequential extraction procedure [37]. This procedure separates the heavy metals in soils into three fractions, i.e., exchangeable and carbonate-associated (F1), reducible (bound to $\mathrm{Fe} / \mathrm{Mn}$ oxides, F2), and oxidizable (bound to OM, F3) fractions, which are extracted by $0.11 \mathrm{~mol} / \mathrm{L}$ acetic acid solution, $0.1 \mathrm{~mol} / \mathrm{L}$ hydroxylamine 
hydrochloride solution adjusted to $\mathrm{pH} 2.0$ with $\mathrm{HNO}_{3}$, and $1 \mathrm{~mol} / \mathrm{L}$ ammonium acetate solution after digestion with $\mathrm{H}_{2} \mathrm{O}_{2}$, respectively. To obtain the mass balance of heavy metals in the soils, the residual fraction (F4) was measured after acid digestion using the procedure described above for total metal determination. The recoveries, which were defined as the sum of F1, F2, F3, and F4 divided by the total content, ranged from $108 \%$ to $120 \%$.

2.4. Statistical Analysis. One way ANOVA test was used to statistically analyze the difference between the data sets. Pearson's correlation was performed to obtain the correlation of heavy metal speciation during aging experiments. Statistical analyses were performed with the statistical software package SPSS version 20.0 for Windows.

\section{Results}

3.1. Soil Characteristics and Geochemical Fractions of Heavy Metals in the Native Soils. The soil characteristics were shown in Table 1 . The red soil was slightly alkaline $(\mathrm{pH}=7.17)$ and brown soil was more acidic than red soil ( $\mathrm{pH}=4.58)$. Low soil $\mathrm{pH}$ is considered to have an adverse effect on the stabilization of exogenous heavy metals $[38,39]$. Brown soil from farmland contained more OM, indicating a relatively high ability to bind and retain heavy metals [40]. DCB-Fe/Al/Mn oxides, including free crystalline and amorphous $\mathrm{Fe} / \mathrm{Al} / \mathrm{Mn}$ oxides, play a significant role in the aging of soil heavy metals [18]. Concentrations of $\mathrm{DCB}-\mathrm{Fe} / \mathrm{Al} / \mathrm{Mn}$ in red soil were higher than that of brown soil. Fe/Al/Mn oxides in soils can strongly bond heavy metals via coprecipitation, adsorption, surface complex formation, ion exchange, and penetration of the crystal lattice [41]. The CEC values of the two soils were comparable with 5.41 and $5.89 \mathrm{cmol}_{\mathrm{c}} / \mathrm{kg}$, respectively. Sand was the major fraction for the red and brown soils, with values of $61.2 \%$ and $81.2 \%$, respectively. The concentrations of $\mathrm{Cd}$, $\mathrm{Cu}$, and $\mathrm{Pb}$ were $0.09,18.2$, and $29.2 \mathrm{mg} / \mathrm{kg}$ in red soil and $0.09,11.4$, and $18.9 \mathrm{mg} / \mathrm{kg}$ in brown soil, respectively, and lower than risk screening values for soil contamination of agricultural land of China (GB 15618-2018) [36], indicating no pollution by $\mathrm{Cd}, \mathrm{Cu}$, and $\mathrm{Pb}$.

As mentioned above, the soils were both not polluted by $\mathrm{Cd}, \mathrm{Cu}$, and $\mathrm{Pb}$. F1 fraction proportion of $\mathrm{Cd}$ was $25.2 \%$ and $34.2 \%$ in red soil and brown soil, respectively (Figure 1). Due to low content, an F3 fraction of Cd cannot be detected for both soils. The bioavailable fraction of $\mathrm{Cu}$ (i.e., F1 fraction) was relatively low in red and brown soils, with values of $2.7 \%$ and $10.15 \%$, respectively, and the proportion of $\mathrm{F} 4$ fraction was highest. For $\mathrm{Pb}$, the percentage of $\mathrm{F} 1$ fraction was $26.4 \%$ in red soil, while the lower percentage of F1 fraction was found in brown soil (5.0\%). Moreover, the F2 fraction of $\mathrm{Pb}$ was high in both soils. The total concentration of heavy metals and bioavailable fraction concentrations of heavy metals in native soil were both lower than spiked heavy metals; hence the effect of $\mathrm{Cd}, \mathrm{Cu}$, and $\mathrm{Pb}$ in native soil on the aging process can be ignored.
3.2. Heavy Metal Aging under Different Incubation Temperatures. The time-dependent fraction transformations of $\mathrm{Cd}, \mathrm{Cu}$, and $\mathrm{Pb}$ under different incubation temperatures were shown in Figures 2-4, respectively. The concentration of F1 fraction was extremely increased when exogenous heavy metals were added in the soils. Thus, the proportion of $\mathrm{F} 1$ fraction was predominant for $\mathrm{Cd}$ and $\mathrm{Cu}$ during all incubation experiments, and the proportion of $\mathrm{F} 1$ fraction of $\mathrm{Pb}$ was relatively high as well. The proportions of $\mathrm{F} 1$ fraction of $\mathrm{Cd}$ and $\mathrm{Pb}$ slightly reduced for 5-45 days of incubation for all cases and changed less after 45 days. For $\mathrm{Cu}$, the proportion of $\mathrm{F} 1$ fraction changed less with incubation time at $5^{\circ} \mathrm{C}$ and $10^{\circ} \mathrm{C}$, while the proportion of $\mathrm{F} 1$ fraction in the two soils both slightly decreased with incubation time at $25^{\circ} \mathrm{C}$. After 145 days of incubation at a different temperature, the proportions of $\mathrm{F} 1$ fraction of $\mathrm{Cd}$, $\mathrm{Cu}$, and $\mathrm{Pb}$ ranged in $82.2 \%-90.0 \%, 51.0 \%-74.9 \%$, and $27.2 \%-43.8 \%$, respectively.

During the whole aging process under different temperatures, $\mathrm{Pb}$ in the $\mathrm{F} 2$ fraction was predominant, ranging from $46.1 \%$ to $55.5 \%$ in the red soil and $55.1 \%$ to $67.1 \%$ in the brown soil, respectively. A relatively lower proportion of $\mathrm{F} 2$ fraction of $\mathrm{Cd}$ and $\mathrm{Cu}$ was found during the incubation period, ranging from $6.8 \%$ to $18.5 \%$ for $\mathrm{Cd}$ and $15.1 \%$ to $33.3 \%$ for $\mathrm{Cu}$, respectively. The proportion of F2 fractions of $\mathrm{Cd}, \mathrm{Cu}$, and $\mathrm{Pb}$ changed less or slightly increased during 5-145 days of incubation for all cases, while the amount of F2 fraction of heavy metals was higher than that in native soils. F3 fractions of $\mathrm{Cd}, \mathrm{Cu}$, and $\mathrm{Pb}$ were all relatively low and gradually increased with incubation time. After incubation, percentages of $\mathrm{F} 3$ fraction ranged in $0.8 \%-4.8 \%$ for $\mathrm{Cd}, 2.4 \%-6.1 \%$ for $\mathrm{Cu}$, and $2.4 \%-4.6 \%$ for $\mathrm{Pb}$, respectively.

\subsection{Heavy Metal Aging under Different Soil Water Contents.} Change patterns of heavy metal geochemical fractions under different water content were shown in the Figures 5-7. The rapid decrease of F1 fraction of heavy metals was not observed, and F1 proportion of heavy metals was relatively high, which were consistent with the results of the experiments under different incubation temperatures. During the incubation period, the proportions of $\mathrm{F} 1$ fraction of $\mathrm{Cd}$ and $\mathrm{Cu}$ were slightly decreased. The proportion of F1 fraction of $\mathrm{Pb}$ slightly decreased first, then slightly increased after 45 days of incubation. After 145 days of incubation, the percentage of $\mathrm{F} 1$ fraction ranged from $77.3 \%$ to $87.3 \%$ for $\mathrm{Cd}$, $46.1 \%-66.4 \%$ for $\mathrm{Cu}$, and $24.8 \%-41.4 \%$ for $\mathrm{Pb}$, respectively. F2 and F3 fractions of Cd slightly increased with incubation time. For $\mathrm{Cu}$ and $\mathrm{Pb}$, the obvious change of $\mathrm{F} 2$ fraction with incubation time was not found, while the obvious increase of $\mathrm{F} 3$ fraction of $\mathrm{Cu}$ and $\mathrm{Pb}$ can be found with incubation time. The proportion of $\mathrm{F} 4$ fraction of $\mathrm{Cd}$ and $\mathrm{Cu}$ slightly increased with incubation time, but the $\mathrm{F} 4$ fraction was below 3.0\% for $\mathrm{Cd}$ and $15.0 \%$ for $\mathrm{Cu}$, respectively. For $\mathrm{Pb}$, the low and unchanged proportion of F4 fraction was found, ranging from $5.6 \%$ to $7.0 \%$. 
TABle 1: Physicochemical properties of the soil samples.

\begin{tabular}{|c|c|c|c|c|c|c|c|c|c|c|c|c|}
\hline \multirow[t]{2}{*}{ Soil samples } & \multirow[t]{2}{*}{$\mathrm{pH}$} & \multirow[t]{2}{*}{ CEC $\left(\mathrm{cmol}_{\mathrm{c}} / \mathrm{kg}\right)$} & \multirow[t]{2}{*}{$\mathrm{OM}(\mathrm{g} / \mathrm{kg})$} & \multicolumn{3}{|c|}{ Soil texture (\%) } & \multicolumn{3}{|c|}{$\begin{array}{c}\text { Total heavy metal } \\
\text { concentrations } \\
(\mathrm{mg} / \mathrm{kg})\end{array}$} & \multicolumn{3}{|c|}{$\begin{array}{l}\text { DCB-metal oxides } \\
(\mathrm{g} / \mathrm{kg})\end{array}$} \\
\hline & & & & Clay & Silt & Sand & $\mathrm{Cd}$ & $\mathrm{Cu}$ & $\mathrm{Pb}$ & $\mathrm{Al}$ & $\mathrm{Fe}$ & $\mathrm{Mn}$ \\
\hline Red soil & 7.17 & 5.41 & 7.1 & 5.1 & 33.8 & 61.2 & 0.09 & 18.2 & 29.2 & 1.84 & 11.64 & 0.33 \\
\hline Brown soil & 4.58 & 5.89 & 12.1 & 1.4 & 17.4 & 81.2 & 0.09 & 11.4 & 18.9 & 0.92 & 4.98 & 0.28 \\
\hline
\end{tabular}

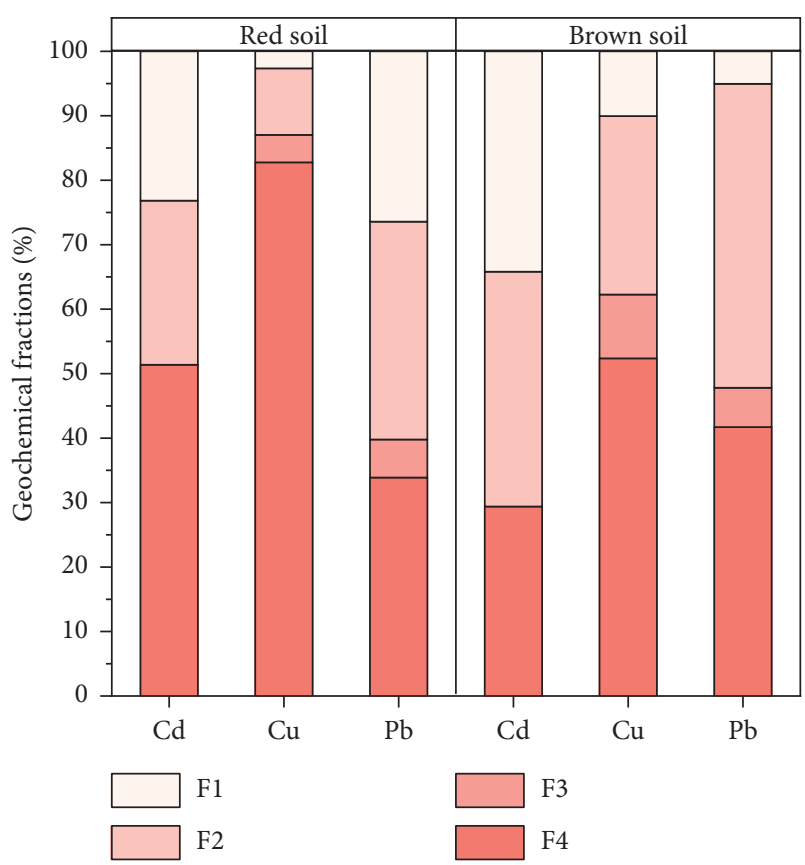

Figure 1: Geochemical fractions of heavy metals in native soil.

\section{Discussion}

4.1. Aging Process. In the present study, a rapid reduction of $\mathrm{F} 1$ fraction of $\mathrm{Cd}, \mathrm{Cu}$, and $\mathrm{Pb}$ was not observed, indicating that most spiked heavy metals (soluble form) had transformed into more stable fractions within 5 days of incubation in the tested soils. The result was not consistent with other studies, in which rapid reduction of bioavailable $\mathrm{Cd}$, $\mathrm{Cu}$, and $\mathrm{Pb}$ was found within 10-20 days after adding heavy metals [20-22]. The concentrations of heavy metals in other aging experiments were $30 \mathrm{mg} / \mathrm{kg}$ for $\mathrm{Cd}, 500 \mathrm{mg} / \mathrm{kg}$ for $\mathrm{Cu}$ and $\mathrm{Pb}$, and higher than heavy metal concentrations in the present study, which might be the reason for the rapid reduction of bioavailable $\mathrm{Cd}, \mathrm{Cu}$, and $\mathrm{Pb}$ within 5 days. In addition, the difference in soil properties, such as OM, CEC, and $\mathrm{Fe}$ oxides, should be another reason for the rapid transformation of spiked heavy metals in the present study. Although the bioavailable fraction of spiked heavy metals was decreased in a short-time incubation, their concentration and proportion were still high, indicating a higher environmental risk.

The decrease of F1 fraction and the slight increase of other fractions during the incubation period indicated that F1 fractions transformed into more stable fractions after adding exogenous heavy metals. The results were also supported by Pearson's correlation (Table 2). Under different incubation temperatures, the correlations between F1 and $\mathrm{F} 2$ fractions of $\mathrm{Cd}, \mathrm{Cu}$, and $\mathrm{Pb}$ were all negative and very significant $(p<0.01)$. Similarly, the very significant $(p<0.01)$ and negative correlations between F1 and F2 fractions were also observed for $\mathrm{Cd}, \mathrm{Cu}$, and $\mathrm{Pb}$ under different soil water content. The results indicated that most introduced heavy metals converted to F2 fraction during incubation. In addition, other fractions presented a strong correlation as well. For the aging experiment under different temperatures, some significant $(p<0.05)$ or very significant $(p<0.01)$ correlations among F2, F3, and F4 were observed. Significant $(p<0.05)$ or very significant $(p<0.01)$ correlations between F2 and F3 fractions of heavy metals were also found for the aging experiment under different soil water content. The result both indicated that the transformation among F2, F3, and F4 should occur during incubation.

4.2. Influence of Factors on Aging of Soil Heavy Metals. Soil property is a crucial factor affecting the aging process of heavy metals $[23,28,42]$. Fe/Mn oxides in soils can strongly bond heavy metals via coprecipitation, adsorption, surface complex formation, ion exchange, and penetration of the crystal lattice [40]. Higher soil $\mathrm{pH}$ can enhance the negative charge on the surface of soil particles and induce precipitation of heavy metals [43]. In addition, higher $\mathrm{pH}$ can promote precipitation/nucleation by the formation of $\mathrm{Me}(\mathrm{OH})^{+}$on the surfaces of soil solids, where proton dissociation from water molecules often takes place more readily than in bulk solutions [23]. The $\mathrm{pH}$ and content of DCB-Al/Fe/Mn were lower in brown soil than red soil, which seems to conclude the stronger ability of red soil to stabilizing exogenous heavy metals. However, it can be found that the obvious patterns of the speciation distribution of heavy metals were higher for the $\mathrm{F} 1$ and F3 fractions (ANOVA, $p<0.05$ ) and lower for the F2 fraction (ANOVA, $p<0.05$ ) in the red soil compared to the brown soil. Notably, the content of soil OM of brown soil was higher than red soil. Thus, it can be deduced that soil OM should be more important than other soil properties for heavy metal aging in the present study. Soil OM possesses a great number and variety of functional groups, which enhance the heavy metal adsorption capacity primarily by surface complexation, ion exchange, and surface precipitation [43-45]. Beyond that, the dominant fraction of different heavy metals was obviously different during the incubation period. It was observed that most $\mathrm{Pb}$ existed in F2 fraction, while dominant portions of $\mathrm{Cd}$ and $\mathrm{Cu}$ were $\mathrm{F} 1$ fraction during the whole incubation period. The result suggested that the transformation rate followed the order: $\mathrm{Pb}>\mathrm{Cu}>\mathrm{Cd}$. 


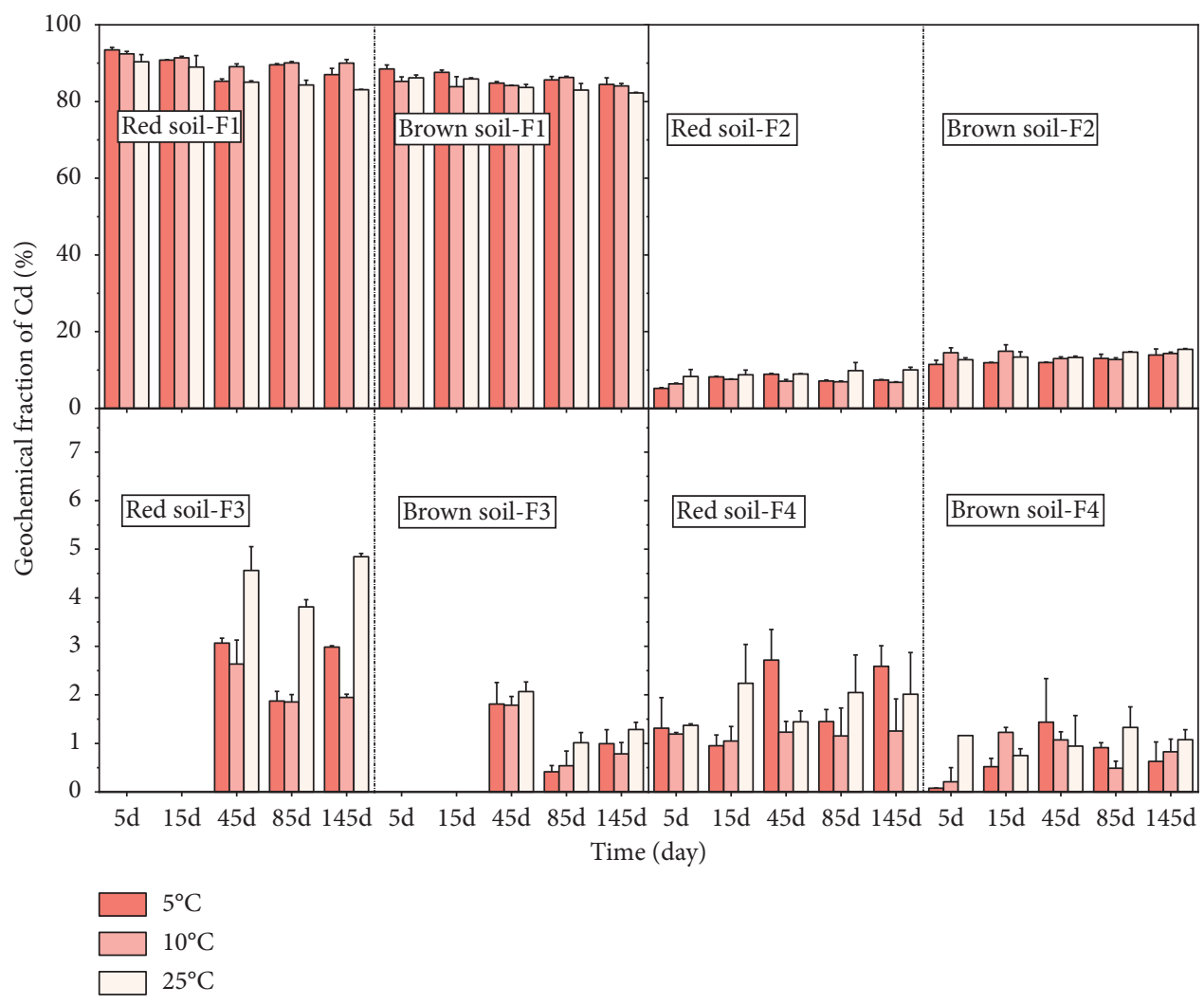

Figure 2: Changes in Cd fractions in soils at different temperatures as a function of contact time.

TABLE 2: Pearson's correlation of heavy metal speciation during aging experiments.

\begin{tabular}{|c|c|c|c|c|c|}
\hline \multicolumn{2}{|c|}{ Heavy metal speciation } & $\mathrm{F} 1$ & F2 & F3 & $\mathrm{F} 4$ \\
\hline \multirow{4}{*}{$\mathrm{Cd}$} & F1 & 1 & $-0.624^{* *}$ & $-0.336^{*}$ & -0.176 \\
\hline & $\mathrm{F} 2$ & $-0.0815^{* *}$ & $\frac{1}{1}$ & $-{\underline{0.371^{*}}}^{*}$ & $-0.336^{*}$ \\
\hline & F3 & $-0.375^{*}$ & -00.212 & $\overline{1}$ & $0 . \overline{488}^{* *}$ \\
\hline & $\mathrm{F} 4$ & -0.029 & $-0.443^{*}$ & $0.578^{* *}$ & $\frac{1}{1}$ \\
\hline \multirow{4}{*}{$\mathrm{Cu}$} & F1 & 1 & $-0.950^{* *}$ & 0.268 & $-0.810^{* *}$ \\
\hline & F2 & $-0.971^{* *}$ & $\overline{1}$ & $-\overline{0.526}^{* *}$ & $0_{0.608^{*} *}$ \\
\hline & F3 & 0.116 & -0.315 & $\overline{1}$ & $\overline{0.117}$ \\
\hline & $\mathrm{F} 4$ & $-0.870^{* *}$ & $0.759^{* *}$ & 0.036 & 1 \\
\hline \multirow{4}{*}{$\mathrm{Pb}$} & F1 & 1 & $-0.991^{* *}$ & $\underline{0.640}^{* *}$ & $-\underline{0.200}$ \\
\hline & $\mathrm{F} 2$ & $-0.993^{* *}$ & $\frac{1}{1}$ & $-\underline{-0.695}^{* *}$ & 0.154 \\
\hline & F3 & $0.519^{* *}$ & $-0.590^{* *}$ & $\frac{1}{1}$ & -0.258 \\
\hline & $\mathrm{F} 4$ & -0.293 & 0.251 & $-0.465^{* *}$ & $\overline{1}$ \\
\hline
\end{tabular}

${ }^{*}$ Correlation is significant at the level (2-tailed). ${ }^{* *}$ Correlation is significant at the 0.01 level (2-tailed); values in italics denote Pearson's correlation coefficient for aging experiments under different temperatures, $n=30$; underlined values denote Pearson's correlation coefficient for aging experiments under different water contents of soils, $n=40$.

$\mathrm{F} 1$ proportions of $\mathrm{Cd}$ and $\mathrm{Cu}$ at $5^{\circ} \mathrm{C}$ and $10^{\circ} \mathrm{C}$ were both significantly higher than that at $25^{\circ} \mathrm{C}$ during incubation (ANOVA, $p<0.05$ for $\mathrm{Cd}$ and $p<0.01$ for $\mathrm{Cu}$ ). While F2 fractions of $\mathrm{Cd}$ at $5^{\circ} \mathrm{C}$ and $10^{\circ} \mathrm{C}$ were both significantly lower than that at $25^{\circ} \mathrm{C}$ (ANOVA, $p<0.05$ ). For $\mathrm{Cu}$, only brown soil presented higher $\mathrm{F} 2$ fraction at $5^{\circ} \mathrm{C}$ and $10^{\circ} \mathrm{C}$ than that at $25^{\circ} \mathrm{C}$ (ANOVA, $p<0.05$ ). The significant difference for $\mathrm{Pb}$ was not found at different incubation temperatures (ANOVA, $p<0.05$ ), but after incubation, F1 fraction of $\mathrm{Pb}$ at $25^{\circ} \mathrm{C}$ was lower than that at low temperature and $\mathrm{F} 2$ fraction of $\mathrm{Pb}$ at $25^{\circ} \mathrm{C}$ was higher than that at low temperature. The results indicated that enhancing incubation temperature can accelerate the transformation of spiked heavy metals. It has been reported that increasing temperature can accelerate the adsorption of heavy metal ions on the soil particle surface and the diffusion of heavy metal ions into interlayers of soil minerals, affecting the aging mechanisms $[23,30]$. The result agreed with the aging process of As at different temperatures [30].

During incubation, the difference of $\mathrm{F} 1$ fraction among various water content experiments did not reach a 


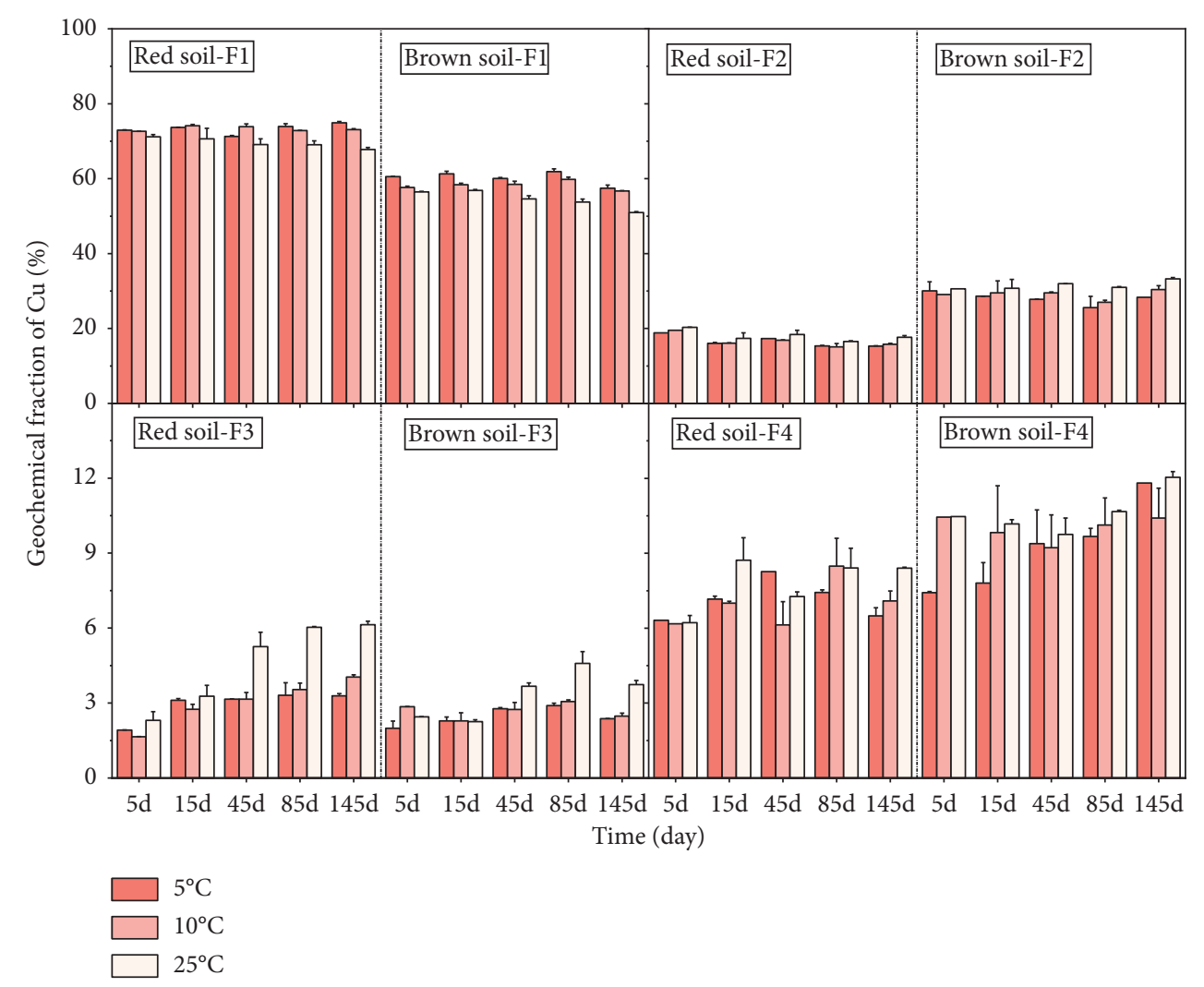

Figure 3: Changes of $\mathrm{Cu}$ fractions in soils at different temperatures as a function of contact time.

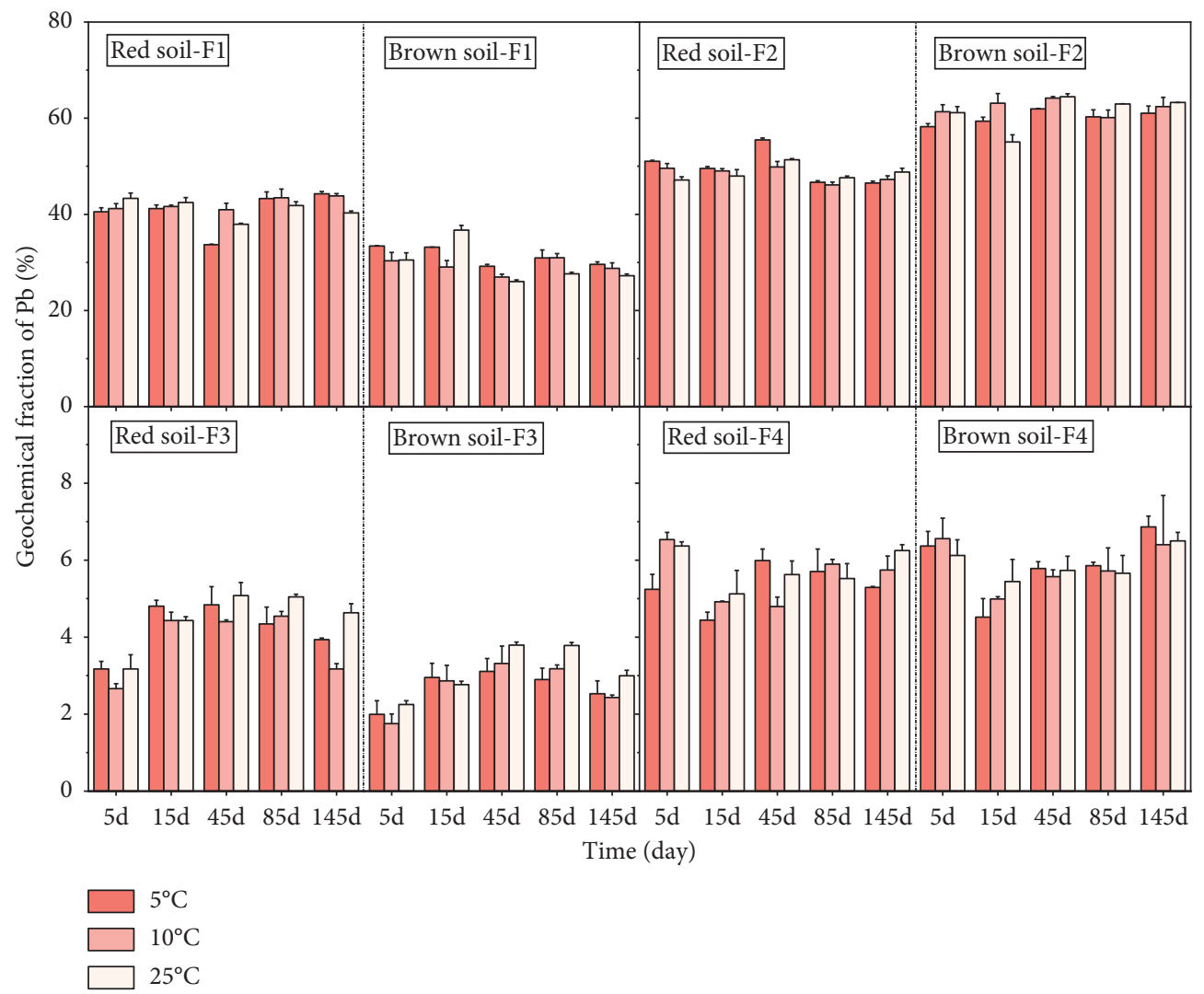

FIgURE 4: Changes of $\mathrm{Pb}$ fractions in soils at different temperatures as a function of contact time. 


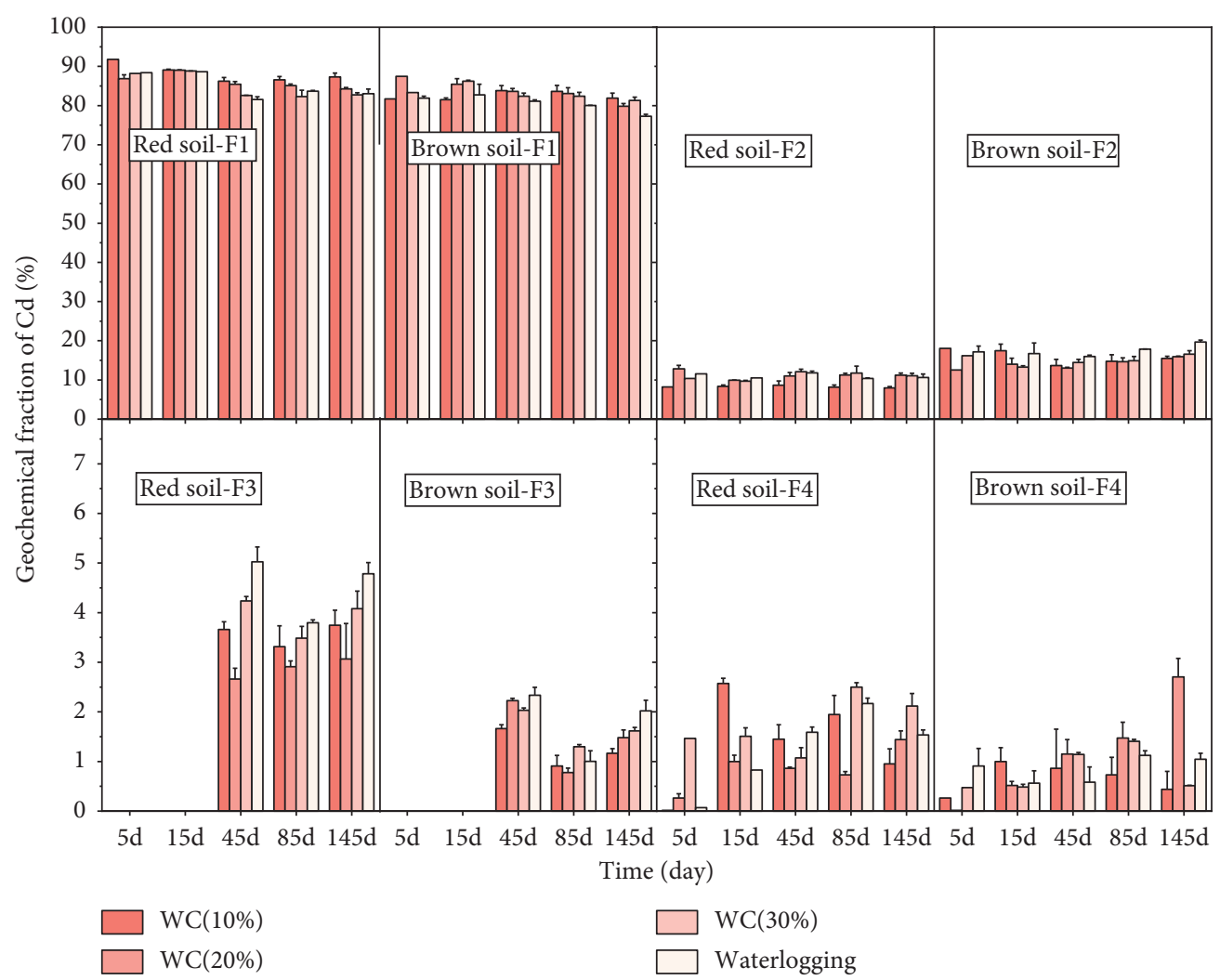

Figure 5: Changes of Cd fractions in different soil water contents as a function of contact time.

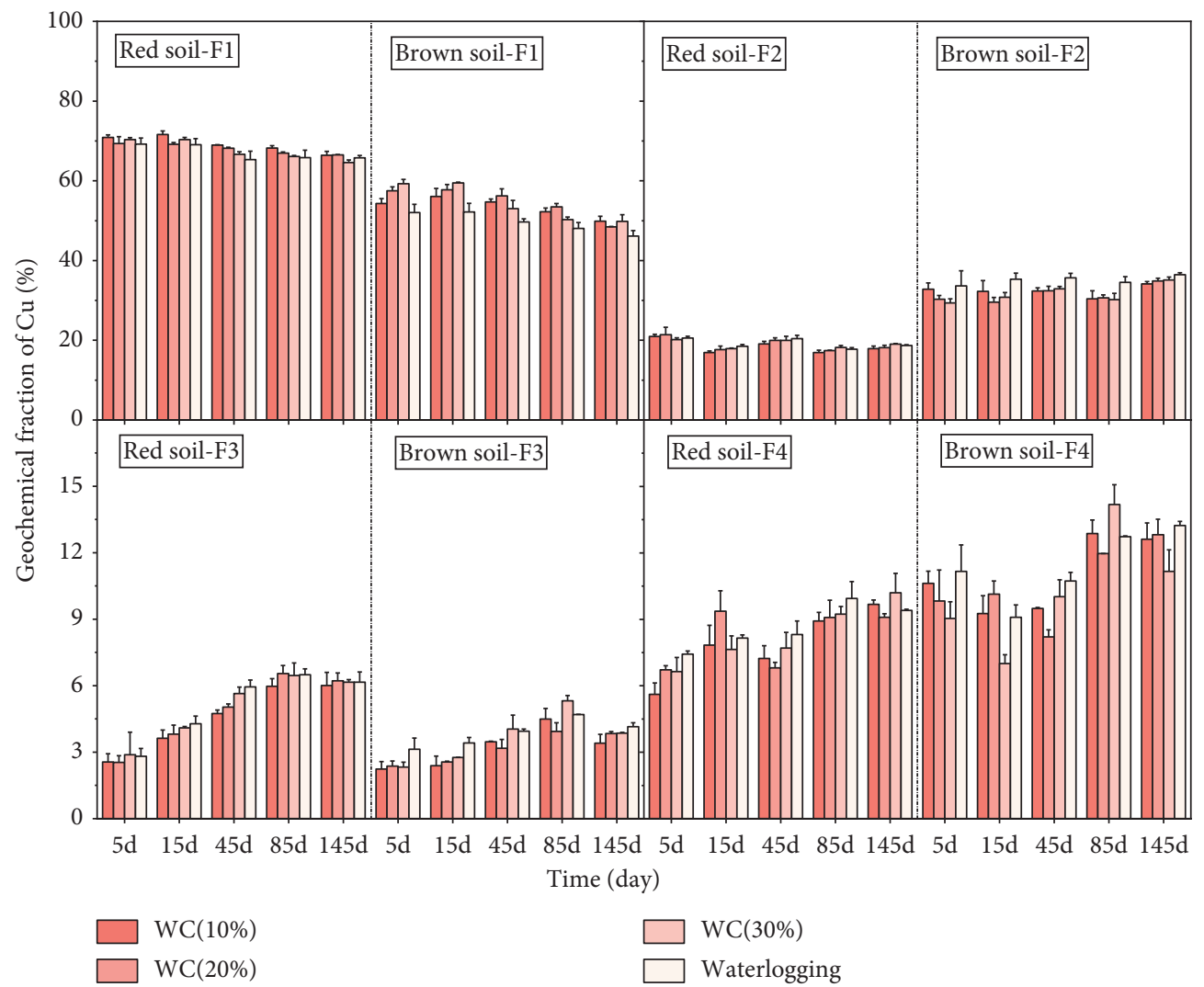

Figure 6: Changes of $\mathrm{Cu}$ fractions in different soil water contents as a function of contact time. 


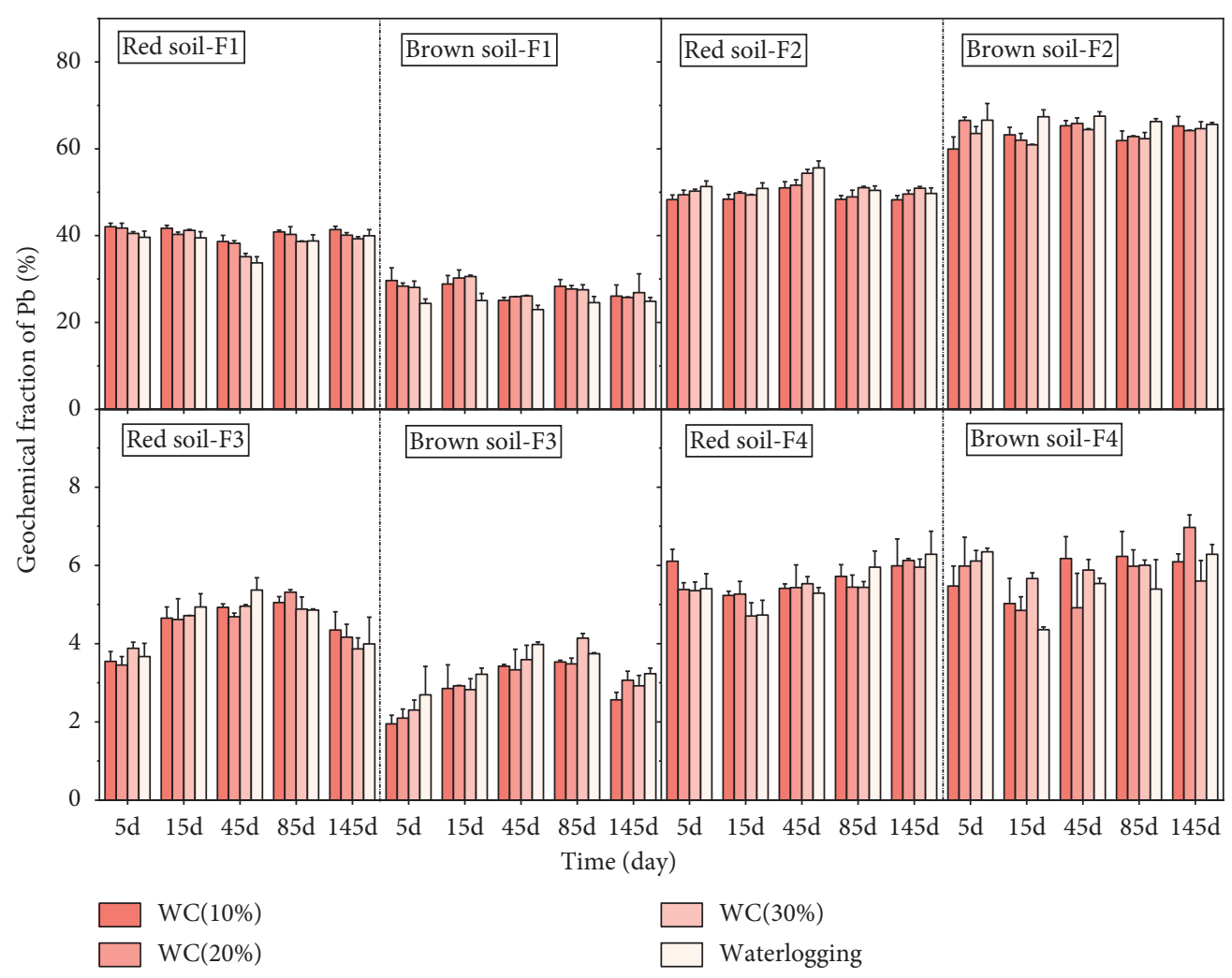

FIgURE 7: Changes of $\mathrm{Pb}$ fractions in different soil water contents as a function of contact time.

significant level for all cases. However, it can be found that, after 145 days of incubation, the proportions of F1 fraction of heavy metals were all lower for high water content experiments than low water content experiments. Conversely, the proportions of $\mathrm{F} 2$ fraction of heavy metals were all higher for high water content experiments. The results suggested that the water content of soils is one of the key factors of speciation redistribution of heavy metals after adding heavy metals. Change patterns of soil properties, such as $\mathrm{Eh}, \mathrm{pH}$, and $\mathrm{Fe} / \mathrm{Al}$ oxides, are different under various water content, therefore induce the different change patterns of heavy metal speciation [20]. High soil water content can reduce oxygen diffusion and generate a reducing condition [46]. In addition, a part of Fe oxides can be dissolved under low $\mathrm{Eh}$, and form less crystal Fe oxide, which possesses a high affinity for heavy metal ions [20,47]. The processes of dissolution and recrystallization make heavy metals coprecipitation with Fe [48]. The formation of insoluble sulfide with heavy metals may be another cause of the reduction of F1 fraction under lower Eh [49]. Moreover, high water content during the aging experiment can increase soil $\mathrm{pH}[20]$. With the increase in soil $\mathrm{pH}$, the hydroxyl $(-\mathrm{OH})$ groups of $\mathrm{OM}$ and metal oxides and carboxyl $(-\mathrm{COOH})$ of $\mathrm{OM}$ can be converted to $-\mathrm{COO}^{-}$ and- $\mathrm{O}^{-}$, significantly increasing the negative charge $[43,45]$. Moreover, high $\mathrm{pH}$ can result in an increase of adsorption and coprecipitation of heavy metals on metal oxides [50].

\section{Conclusions}

Aging of soil heavy metals is very significant for reducing their bioavailable fraction when heavy metals are discharged into the soil. In the present study, most introduced $\mathrm{Cd}, \mathrm{Cu}$, and $\mathrm{Pb}$ were transformed from soluble fraction to more stable fractions within 5 days of incubation, which was faster than other studies. Relatively lower concentrations of introduced heavy metals accounted for their rapid stabilization. The types of heavy metals and soils both affect the aging process. Based on the proportions of various fractions during incubation, it can be found that the transformation rate followed the order: $\mathrm{Pb}>\mathrm{Cu}>\mathrm{Cd}$, and soil $\mathrm{OM}$ was the primary factor impacting the stabilization of soil heavy metals in the present study. During incubation, a higher proportion of $\mathrm{F} 1$ fraction of $\mathrm{Cd}$ and $\mathrm{Cu}$ and lower proportion of $\mathrm{F} 2$ fraction of $\mathrm{Cd}$ and $\mathrm{Cu}$ at $5^{\circ} \mathrm{C}$ and $10^{\circ} \mathrm{C}$ were observed than that at $25^{\circ} \mathrm{C}$. Meanwhile, a lower proportion of $\mathrm{F} 1$ fraction of the heavy metals and a higher proportion of F2 fraction of the heavy metals were observed at waterlogged soil after incubation. The aging of soil heavy metals was accelerated under high temperature and soil water content. The result can contribute to assessing the environmental risk of soil heavy metal pollution.

\section{Data Availability}

The data used to support the findings of this study are available from the corresponding author upon request. 


\section{Conflicts of Interest}

The authors declare that they have no conflicts of interest.

\section{Acknowledgments}

This work was financially supported by the National Natural Science Foundation of China (41807134), Geological Survey Project of China (DD20190182), and Fundamental Research Funds for the Chinese Academy of Geological Sciences (K0905).

\section{References}

[1] L. Rodríguez, E. Ruiz, J. Alonso-Azcárate, and J. Rincón, "Heavy metal distribution and chemical speciation in tailings and soils around a $\mathrm{Pb}-\mathrm{Zn}$ mine in Spain," Journal of Environmental Management, vol. 90, no. 2, pp. 1106-1116, 2009.

[2] J. Wang, G. Liu, H. Wu, T. Zhang, X. Liu, and W. Li, "Temporal-spatial variation and partitioning of dissolved and particulate heavy metal (loid) $s$ in a river affected by mining activities in Southern China," Environmental Science and Pollution Research, vol. 25, no. 10, pp. 9828-9839, 2018.

[3] G. Liu, L. Tao, X. Liu, J. Hou, A. Wang, and R. Li, "Heavy metal speciation and pollution of agricultural soils along Jishui River in non-ferrous metal mine area in Jiangxi Province, China," Journal of Geochemical Exploration, vol. 132, no. 9, pp. 156-163, 2013.

[4] L. Chen, Z. Xu, M. Liu et al., "Lead exposure assessment from study near a lead-acid battery factory in China," Science of the Total Environment, vol. 429, pp. 191-198, 2012.

[5] J. Hou, G.-N. Liu, W. Xue, W.-J. Fu, B.-C. Liang, and X.-H. Liu, "Seed germination, root elongation, root-tip mitosis, and micronucleus induction of five crop plants exposed to chromium in fluvo-aquic soil," Environmental Toxicology and Chemistry, vol. 33, no. 3, pp. 671-676, 2014.

[6] G. Kalyvas, D. Gasparatos, C. A. Liza, and I. Massas, "Single and combined effect of chelating, reductive agents, and agroindustrial by-product treatments on $\mathrm{As}, \mathrm{Pb}$, and $\mathrm{Zn}$ mobility in a mine-affected soil over time," Environmental Science and Pollution Research, vol. 27, no. 5, pp. 5536-5546, 2020.

[7] M. Taghipour, S. Ayoubi, and H. Khademi, "Contribution of lithologic and anthropogenic factors to surface soil heavy metals in western Iran using multivariate geostatistical analyses," Soil and Sediment Contamination: An International Journal, vol. 20, no. 8, pp. 921-937, 2011.

[8] S. Ayoubi, V. Adman, and M. Yousefifard, "Use of magnetic susceptibility to assess metals concentration in soils developed on a range of parent materials," Ecotoxicology and Environmental Safety, vol. 168, pp. 138-145, 2019.

[9] G. Liu, W. Xue, J. Wang, and X. Liu, "Transport behavior of variable charge soil particle size fractions and their influence on cadmium transport in saturated porous media," Geoderma, vol. 337, pp. 945-955, 2019.

[10] S. Mor, K. Ravindra, R. P. Dahiya, and A. Chandra, "Leachate characterization and assessment of groundwater pollution near municipal solid waste landfill site," Environmental Monitoring and Assessment, vol. 118, no. 1-3, pp. 435-456, 2006.

[11] V. Ličina, M. F. Akšić, Z. Tomić et al., "Bioassessment of heavy metals in the surface soil layer of an opencast mine aimed for its rehabilitation," Journal of Environmental Management, vol. 186, pp. 240-252, 2017.
[12] G. Liu, J. Wang, E. Zhang, J. Hou, and X. Liu, "Heavy metal speciation and risk assessment in dry land and paddy soils near mining areas at Southern China," Environmental Science and Pollution Research, vol. 23, no. 9, pp. 8709-8720, 2016.

[13] A. A. Abdelhafez, H. H. Abbas, R. S. Abd-El-Aal, N. F. Kandil, J. Li, and W. Mahmoud, "Environmental and health impacts of successive mineral fertilization in Egypt," CLEAN-Soil, Air, Water, vol. 40, no. 4, pp. 356-363, 2012.

[14] X. Chen, X. Xia, Y. Zhao, and P. Zhang, "Heavy metal concentrations in roadside soils and correlation with urban traffic in Beijing, China," Journal of Hazardous Materials, vol. 181, no. 1-3, pp. 640-646, 2010.

[15] G. Wu, J.-Y. Wu, and H.-B. Shao, "Hazardous heavy metal distribution in dahuofang catchment, fushun, liaoning, an important industry city in China: a case study," CLEAN-Soil, Air, Water, vol. 40, no. 12, pp. 1372-1375, 2012.

[16] A. M. Sarmiento, A. DelValls, J. M. Nieto, M. J. Salamanca, and M. A. Caraballo, "Toxicity and potential risk assessment of a river polluted by acid mine drainage in the Iberian Pyrite Belt (SW Spain)," Science of the Total Environment, vol. 409, no. 22, pp. 4763-4771, 2011.

[17] L. A. Wendling, J. K. Kirby, and M. J. McLaughlin, “Aging effects on cobalt availability in soils," Environmental Toxicology and Chemistry, vol. 28, no. 8, pp. 1609-1617, 2009.

[18] M. J. McLaughlin, "Ageing of metals in soils changes bioavailability in: Fact sheet on environmental risk assessment," International Council on Metals and the Environment, vol. 4, pp. 1-6, 2001.

[19] P. Dousis, I. Anastopoulos, D. Gasparatos, C. Ehaliotis, and I. Massas, "Effects of time and glucose-C on the fractionation of $\mathrm{Zn}$ and $\mathrm{Cu}$ in a slightly acidic soil," Communications in Soil Science and Plant Analysis, vol. 44, no. 1-4, pp. 722-732, 2013.

[20] S. A. Zheng, X. Q. Zheng, and C. Chen, "Transformation of metal speciation in purple soil as affected by waterlogging," International Journal of Environmental Science and Technology, vol. 10, no. 2, pp. 351-358, 2013.

[21] S. Zheng and M. Zhang, "Effect of moisture regime on the redistribution of heavy metals in paddy soil," Journal of Environmental Sciences, vol. 23, no. 3, pp. 434-443, 2011.

[22] X. Tang, Y. Zhu, Y. Cui, J. Duan, and L. Tang, "The effect of ageing on the bioaccessibility and fractionation of cadmium in some typical soils of China," Environment International, vol. 32, no. 5, pp. 682-689, 2006.

[23] Y. Ma, E. Lombi, A. L. Nolan, and M. J. McLaughlin, "Shortterm natural attenuation of copper in soils: effects of time, temperature, and soil characteristics," Environmental Toxicology and Chemistry, vol. 25, no. 3, pp. 652-658, 2006.

[24] Y. Yang, Y. Peng, Z. Yang et al., "The kinetics of aging and reducing processes of $\mathrm{Cr}$ (VI) in two soils," Bulletin of Environmental Contamination and Toxicology, vol. 103, no. 1, pp. 82-89, 2019.

[25] E. Smolders and F. Degryse, "Fixation of cadmium and zinc in soils: implications for risk assessment," in Natural Attenuation of Trace Element Availability in Soils, R. Hamon, M. McLaughlin, and E. Lombi, Eds., pp. 157-169, CRC, Boca Raton, FL, USA, 2007.

[26] X. Zhang, S. Zeng, S. Chen, and Y. Ma, "Change of the extractability of cadmium added to different soils: aging effect and modeling," Sustainability, vol. 10, no. 3, p. 885, 2018.

[27] S. Zheng, X. Zheng, S. Liu, and X. Yao, "Aging process of Cr (III) in 22 typical soils of China and influence factors analysis," Environmental science, vol. 34, no. 2, pp. 698-704, 2013, (In Chinese). 
[28] Q. Li, H. Du, W. Chen et al., "Aging shapes the distribution of copper in soil aggregate size fractions," Environmental Pollution, vol. 233, pp. 569-576, 2018.

[29] Y. Wang, X. Zeng, Y. Lu et al., "Effect of aging on the bioavailability and fractionation of arsenic in soils derived from five parent materials in a red soil region of Southern China," Environmental Pollution, vol. 207, pp. 79-87, 2015.

[30] G. Huang, Z. Chen, J. Wang, Q. Hou, and Y. Zhang, "Impact of temperature on the aging mechanisms of arsenic in soils: fractionation and bioaccessibility," Environmental Science and Pollution Research, vol. 23, no. 5, pp. 4594-4601, 2016.

[31] X. Chen, Q. Li, Y. Yang et al., "Effects of salinity on the transformation of heavy metals in tropical estuary wetland soil AU-Chu Bei," Chemistry And Ecology, vol. 31, no. 2, pp. 186-198, 2015.

[32] S. Liang, D.-X. Guan, J. Li, C.-Y. Zhou, J. Luo, and L. Q. Ma, "Effect of aging on bioaccessibility of arsenic and lead in soils," Chemosphere, vol. 151, pp. 94-100, 2016.

[33] M. Jalali and Z. V. Khanlari, "Effect of aging process on the fractionation of heavy metals in some calcareous soils of Iran," Geoderma, vol. 143, no. 1-2, pp. 26-40, 2008.

[34] R. Lu, Analytical Methods of Soil and Agricultural Chemistry (In Chinese), China Agricultural Science and Technology Press, Beijing, China, 1999.

[35] G. Gillman and E. Sumpter, "Modification to the compulsive exchange method for measuring exchange characteristics of soils," Soil Research, vol. 24, no. 1, pp. 61-66, 1986.

[36] Ministry of Ecology and Environment of the People's Republic of China, Soil Environmental Quality: Risk Control Standard for Soil Contamination of Agricultural Land, Ministry of Ecology and Environment of the People's Republic of China S, Beijing, China, (GB15618-2018), 2018.

[37] G. Rauret, J. F. López-Sánchez, A. Sahuquillo et al., "Improvement of the BCR three step sequential extraction procedure prior to the certification of new sediment and soil reference materials," Journal of Environmental Monitoring, vol. 1, no. 1, pp. 57-61, 1999.

[38] G. Liu, W. Xue, L. Tao et al., "Vertical distribution and mobility of heavy metals in agricultural soils along jishui river affected by mining in jiangxi Province, China," CLEAN-Soil, Air, Water, vol. 42, no. 10, pp. 1450-1456, 2014.

[39] F. A. Vega, E. F. Covelo, and M. L. Andrade, "Competitive sorption and desorption of heavy metals in mine soils: influence of mine soil characteristics," Journal of Colloid and Interface Science, vol. 298, no. 2, pp. 582-592, 2006.

[40] G. Liu, J. Wang, X. Liu et al., "Partitioning and geochemical fractions of heavy metals from geogenic and anthropogenic sources in various soil particle size fractions," Geoderma, vol. 312, pp. 104-113, 2018.

[41] T. T. Chao and P. K. Theobald, "The significance of secondary iron and manganese oxides in geochemical exploration," Economic Geology, vol. 71, no. 8, pp. 1560-1569, 1976.

[42] D. Wang, F. Zhou, W. Yang, Q. Peng, N. Man, and D. Liang, "Selenate redistribution during aging in different Chinese soils and the dominant influential factors," Chemosphere, vol. 182, pp. 284-292, 2017.

[43] H. B. Bradl, "Adsorption of heavy metal ions on soils and soils constituents," Journal of Colloid and Interface Science, vol. 277, no. 1, pp. 1-18, 2004.

[44] Y. Refaey, B. Jansen, A.-H. El-Shater, A.-A. El-Haddad, and K. Kalbitz, "The role of dissolved organic matter in adsorbing heavy metals in clay-rich soils," Vadose Zone Journal, vol. 13, no. 7, 2014.
[45] G. Liu, J. Wang, W. Xue, J. Zhao, J. Wang, and X. Liu, "Effect of the size of variable charge soil particles on cadmium accumulation and adsorption," Journal of Soils and Sediments, vol. 17, no. 12, pp. 2810-2821, 2017.

[46] M. C. Chuan, G. Y. Shu, and J. C. Liu, "Solubility of heavy metals in a contaminated soil: effects of redox potential and pH," Water, Air, and Soil Pollution, vol. 90, no. 3-4, pp. 543-556, 1996.

[47] D. Gasparatos, I. Massas, and A. Godelitsas, "Fe-Mn concretions and nodules formation in redoximorphic soils and their role on soil phosphorus dynamics: current knowledge and gaps," Catena, vol. 182, p. 104106, 2019.

[48] H. Y. Yu, F. B. Li, C. S. Liu, W. Huang, T. X. Liu, and W. M. Yu, "Chapter five - iron redox cycling coupled to transformation and immobilization of heavy metals: implications for paddy rice safety in the red soil of south China," in Advances in Agronomy, D. L. Sparks, Ed., vol. 137, pp. 279317, Academic Press, Cambridge, MA, USA, 2016.

[49] D. Zhang, G. Du, D. Chen et al., "Effect of elemental sulfur and gypsum application on the bioavailability and redistribution of cadmium during rice growth," Science of the Total Environment, vol. 657, pp. 1460-1467, 2019.

[50] M. C. Enid and B. MM. Cd, "Cu, Pb, and $\mathrm{Zn}$ coprecipitates in $\mathrm{Fe}$ oxide formed at different $\mathrm{pH}$ : aging effects on metal solubility and extractability by citrate," Environmental Toxicology and Chemistry, vol. 20, no. 1, pp. 122-126, 2001. 